\title{
Governance Strategies to Drive Complementary Innovation in IoT Platforms: A Multiple Case Study
}

\author{
Christian Marheine ${ }^{1}$ \\ ${ }^{1}$ Universität St.Gallen, Institut für Wirtschaftsinformatik, St.Gallen, Schweiz \\ christian.marheinedunisg.ch
}

\begin{abstract}
The widespread uptake of the Internet of Things spurred both software and hardware firms to compete for platform leadership. Information systems research has acknowledged that a platform's success depends on the innovational output of its ecosystem of firms. However, the question whether platform owners should coordinate these firms through cooperative or competitive strategies to create complementary applications remains unaddressed. To address this gap, an exploratory, multiple case study of four German companies with IoT platforms was conducted. Five of the six governance strategies derived from the literature were confirmed: opening, alliancing, coring, entering, and pricing. In these strategies, 19 distinct governance mechanisms and their positive or negative effects were identified. The findings contribute to research on business-tobusiness platforms by demonstrating that cooperation between platform owners and complementors represents the dominant meta-level strategy in IoT platforms.
\end{abstract}

Keywords: Internet of things, IoT platforms, platform governance strategies, complementary innovation, multiple case study research.

\section{Introduction}

Recently, the concept of platforms has received much attention in the Internet of Things (IoT) [1-3]. To give an example, the cloud-computing company Amazon Web Services (AWS) operates an IoT platform. The platform provides companies the functionality to manage millions of devices. In addition, companies that use the AWS platform can also develop their software-based products and services ranging from small add-ons to domain-specific applications. In addition to global players (e.g., Amazon), enterprise software firms (e.g., SAP), automation firms (e.g., Siemens), startups and joint ventures have launched their IoT platforms competing for platform leadership. Analysts forecast that the IoT platform market, which consists of around 450 companies [4], will grow and reach a market value of US $\$ 1.8$ billion by 2022 [5].

So far, information systems (IS) research has acknowledged that the success of a platform depends on the innovative capacity of its ecosystem [6-8]. The ecosystem is a network of independent third-party firms - so-called complementors [7]. These firms develop complementary innovations on top of the platform - apps in particular. A high quantity and variety of complementors, who develop apps, determines a platform's success in complementary innovation $[9,10]$. In addition, more innovation on top of

$15^{\text {th }}$ International Conference on Wirtschaftsinformatik,

March 08-11, 2020, Potsdam, Germany 
the platform will, in turn, attract more end-users to the platform - a phenomenon called indirect network effects [11]. To motivate complementors to join and innovate on top of the platform, owners can apply different governance strategies $[12,13]$. The two dominant meta-level strategies are cooperation and competition [14]. Cooperation focuses on value co-creation [15]. Here, platform owners can share technical resources, such as application programming interfaces (APIs) and software development kits (SDKs) with other firms in the ecosystem. This enables complementors to develop upon the platform $[9,16]$. In contrast, competition seeks to capture more of the value that is co-created [17]. Platform owners can, for example, enter complementary markets with similar products. Due to direct competition, platform owners can take larger shares of complementors' revenue decreasing their incentives to innovate [6,7]. Overall, while cooperation bears on trust and shared goals [7, 18, 19], competition often involves rivalry between platform owners and complementors $[6,20,21]$. Scholars have called for more research on the platform owner's effectiveness of using either of these metalevel strategies for driving complementary innovation [10, 22, 23].

Moreover, most insights on governance strategies and their effectiveness in driving complementary innovation are based on business-to-consumer (B2C) platforms. So far, scholars have studied mobile operating systems (e.g., [24]), video game consoles (e.g., [25]) and social networks (e.g., [26]). The purpose of this paper is to advance our understanding of those strategies applied in business-to-business (B2B) platformsstudying the empirical context of IoT platforms. This motivated the following question: Which cooperative and competitive governance strategies do IoT platform owners apply and how do they affect complementary innovation?

To address this research question, an exploratory, multiple case study of four IoT platforms was conducted. The analysis is based on 13 interviews with platform managers. To guide the analysis and to structure the results, a conceptual framework was derived by systematically reviewing the literature on digital platforms. The framework comprises three cooperative and three competitive governance strategies. The results illustrate that IoT platform owners apply five of the six strategies by using 19 different governance mechanisms. Theses mechanisms are assigned to the strategies showing that cooperation is the dominant meta-level strategy in IoT platforms. The findings contribute to the understanding of platform governance in B2B platforms.

\section{Background on IoT Platforms and Platform Governance}

Following prior work, IoT platforms can be defined as central software-based systems that are operated in the cloud connecting different devices, data sources, developers, and end-users [3, 27]. Compared to digital platforms [14], IoT platforms differ in two things [17, 28]. First, its architectural design is more complex. It comprises four distinct connectivity levels including the device layer, the connectivity layer, the middleware layer, and the application layer [28]. Second, IoT platforms necessitate ecosystems with multiple participants: firms that use the platform and its services (i.e., end-users), firms that develop complementary IoT apps (i.e., complementors), and in addition, firms that build, connect, and maintain devices [29]. 
Offering an IoT platform requires platform owners to make decisions about the ecosystem of complementors beyond just developing and distributing the platform itself $[1,12]$. Platform governance focuses on the relations between platform owners and complementors $[12,13,16]$. Whether a platform owner's governance decisions are successful depends on its effectiveness of stimulating complementors to innovate upon the platform [7]. The incentives to innovate can be created through cooperative and competitive governance strategies [18, 20]. According to the IS and management literature, cooperative strategies include decisions about the platform's optimal degree of openness [9], the formation of strategic partnerships [18] and the platform's technical expandability [30]. In contrast, competitive strategies encompass decisions about the platform owner's entry into complementary markets [21], the pricing structure [20] and the bundling of different functions or features [31]. Based on systematically reviewing the platform literature (see Section 3.1), I derived six governance strategies (i.e., opening, alliancing, coring, entering, pricing and bundling) and synthesized key aspects in a framework - presented in Table 1. The framework assigns aspects that positively $(+)$ or negatively $(-)$ affect complementary innovation to each strategy with exemplary references. Since these strategies are largely based on research on B2C platforms (i.e., 51 of 72 reviewed papers focus on B2C platforms), this paper seeks to test the framework in the IoT context. Next, each strategy is briefly introduced.

Table 1: Governance Strategies Framework

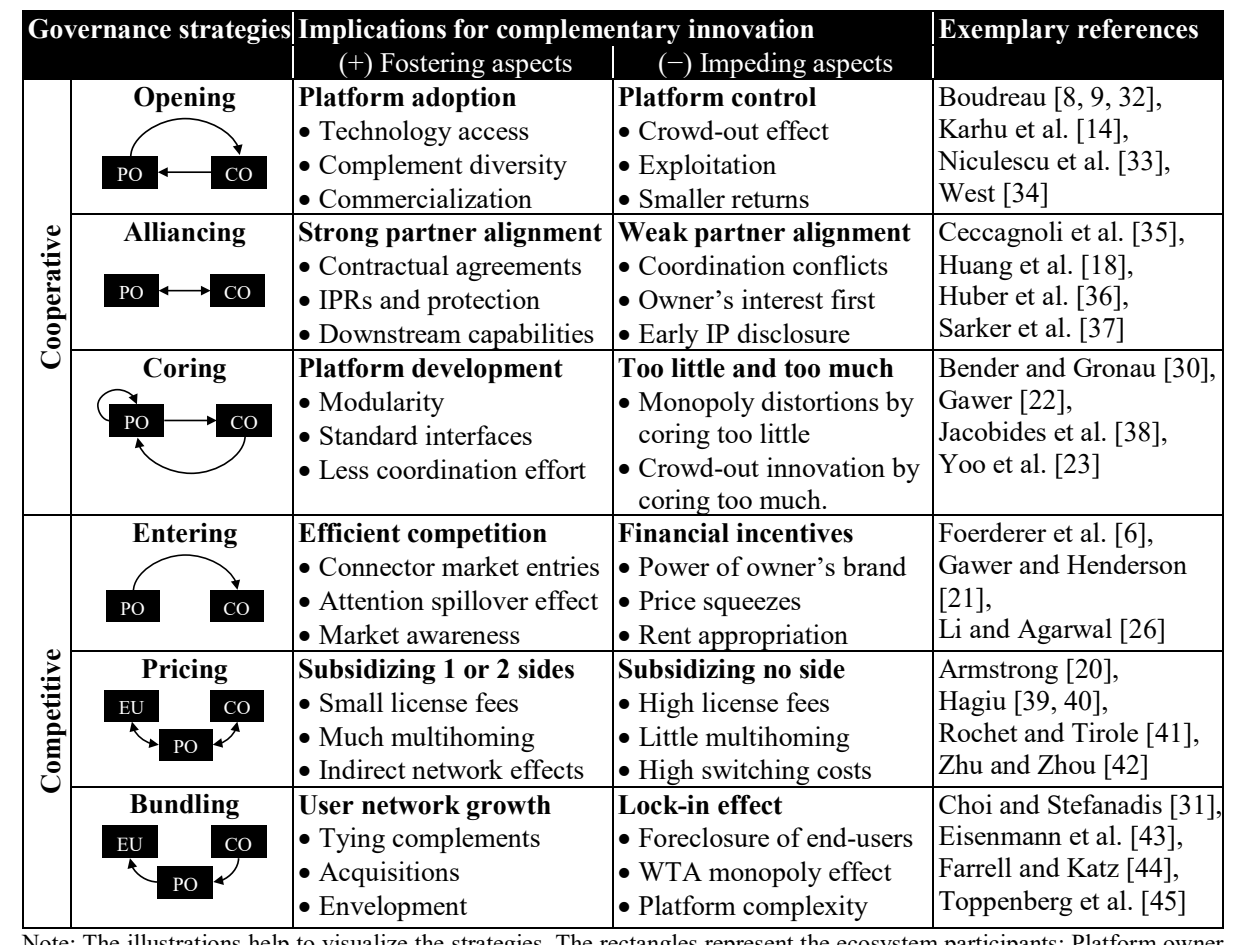

Note: The illustrations help to visualize the strategies. The rectangles represent the ecosystem participants: Platform owner $(\mathrm{PO})$, complementor $(\mathrm{CO})$, and end-user (EU). The arrows represent governance actions and the flow of innovation. 
Opening shifts the locus of value creation from within the firm toward the ecosystem of independent third-party firms [8,9]. The debate on this strategy is about choosing the right degree of openness [14]. An open platform supports a high quantity and variety of complements (i.e., apps) but reduces the platform owner's control of the ecosystem [32]. Alliancing refers to building strategic partnerships that foster value co-creation and capture $[35,37]$. While value co-creation can be stimulated through strategic alignment, trust, and contractual agreements, value capture requires strong downstream capabilities (to market complementary apps) and intellectual property rights (IPRs) like patents $[35,36]$. Coring aims at extending the platform's own codebase. This provides complementors with the latest features that increase their innovation potential [46]. While too much coring can reduce incentives to innovate, too little coring might cause complementors to switch to other, technically better off platforms [30]. To pursue this strategy, platforms must be built as a modular architecture with standard interfaces so that they are readily expandable [22, 23]. Entering is a competitive strategy $[6,26]$. Platform owners enter complementary markets typically to capture a larger portion of the co-created value. On the one hand, the owner's entry can gravitate end-users to the market, stimulating both the sales of platform owners and complementors [6]. On the other hand, a large number of market entries can demotivate complementors to innovate as they could face revenue losses [7, 21]. Pricing decisions encompass taking homing and switching costs into account to determine whether end-users (i.e., demand-side) or complementors (i.e., supply-side) should be subsidized [20, 41]. Pricing decisions promote indirect network effects, that is, the subsidized platform-side may attract the other side to the platform $[11,20]$. Bundling also promotes complementary innovation through indirect network effects [43]. A bundle comprises two or more attractive features offered on a single platform. Bundles can help platform owners to build a monopoly position and deprive others (with just a single key feature) of the opportunity to enter the market with their own platform [31, 43]. Scholars have also referred to this strategy as "tying of complements" [31, p. 55].

\section{Research Methodology}

To answer the research question, an exploratory, multiple case study was conducted following the "linear but iterative process" defined by Yin [47]. A multiple case study was chosen as the appropriate method for conducting this research as the goal was to observe which of the governance strategies have been applied by IoT platform owners, how they have been implemented, and how they affect complementary innovation [47].

\subsection{Systematic Literature Review}

Prior to the case research, the conceptual framework (see Table 1) was developed based on a systematic literature review [48, 49]. The selection process traversed three steps and commenced based on the search string: ("digital platform") AND ("governance" OR “cooperation" OR "competition" OR "innovation"). First, papers were selected based on their outlet with a journal-focus - especially those of the AIS Senior Scholars' 
Basket of Journals - to build a robust fundament. Second, papers were included when their unit of analysis was the platform owner focusing on his activities towards complementors. Finally, a forward and backward search was performed to extend the list with papers whose findings are widely acknowledged among platform experts, e.g., books (e.g., [3, 38]) and Gawer's dissertation [39]. Our selection process resulted in a final sample of 72 papers that were analyzed following a concept-centric approach [48].

\subsection{Case Selection}

To yield robust findings, Eisenhardt suggests "a number between 4 and 10 cases" [50]. To arrive at a manageable sample, the preselection process followed heterogeneous and homogenous sampling [47]. The heterogeneous sampling of companies followed three criteria: (1) the traditional business domain (i.e., software or hardware), (2) the platform approach (i.e., horizontal or vertical) and (3) the firm size in terms of annual revenue (i.e., small, medium or large). In addition, the sampling followed two homogenous criteria to ensure the generalizability of results across different cases. First, all IoT platforms had to comply with the definition of an IoT platform (see Section 2). Second, all IoT platforms had to govern complementors with the goal to drive complementary innovation. The latter criteria were relevant to perform a cross-case analysis [47].

Due to this preselection process, many platforms were excluded that did not comply with the two homogenous criteria (e.g., Bsquare) or did not expand the heterogeneous scope of analysis (e.g., IBM Watson IoT). Moreover, the infrastructure as a service (IaaS) IoT platforms of Google, AWS and Microsoft were excluded, because the focus in this paper was on platform as a service (PaaS) IoT platforms with greater vertical industry focus, such as the industrial IoT. Other platforms were excluded as they did not share their technology with third-party firms (e.g., KONUX). Furthermore, firms situated in Germany were preferred over others in order to facilitate data collection. In addition, IoT platforms were chosen based on literal replication logic, i.e., similar results were expected to be generated from similar platform cases and vice versa [47]. The final sample comprised three of the largest German companies from the enterprise software, engineering, and manufacturing domain and one industrial IoT joint venture (see Table 2).

Table 2: Overview of the Selected IoT Platform Cases

\begin{tabular}{|c|c|c|c|c|c|c|c|c|c|c|c|}
\hline \multirow[t]{3}{*}{ Company } & \multirow[t]{3}{*}{ IoT platform } & \multirow[t]{3}{*}{ First release } & \multicolumn{9}{|c|}{ Characteristics } \\
\hline & & & \multicolumn{2}{|c|}{$\begin{array}{l}\text { Business } \\
\text { domain }\end{array}$} & \multicolumn{2}{|c|}{$\begin{array}{l}\text { Platform } \\
\text { approach }\end{array}$} & \multicolumn{3}{|c|}{ Firm size } & \multicolumn{2}{|c|}{ Ownership } \\
\hline & & & $\begin{array}{l}\text { है } \\
\text { है } \\
\text { है }\end{array}$ & 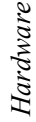 & 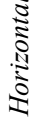 & 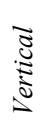 & $\begin{array}{l}8 \\
3 \\
-1\end{array}$ & 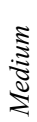 & $\begin{array}{l}\text { छี } \\
\text { हี }\end{array}$ & 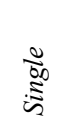 & है \\
\hline PO1 & Platform 1 & 2015 & $\mathrm{X}$ & & X & & & $\mathrm{X}$ & & $\mathrm{X}$ & \\
\hline $\mathrm{PO} 2$ & Platform 2 & 2016 & & $\mathrm{X}$ & $\mathrm{X}$ & & $\mathrm{X}$ & & & $\mathrm{X}$ & \\
\hline $\mathrm{PO} 3$ & Platform 3 & 2016 & & $\mathrm{X}$ & $\mathrm{X}$ & & $\mathrm{X}$ & & & $\mathrm{X}$ & \\
\hline PO4 & Platform 4 & 2017 & $\mathrm{X}$ & & & $\mathrm{X}$ & & & $\mathrm{X}$ & & $\mathrm{X}$ \\
\hline
\end{tabular}


From now on, the four case firms are referred to as platform owners (POs). PO1, a global market leader in enterprise application software, generates an annual revenue of $€ 23$ billion. PO2 is a leader in automation technology with an annual revenue exceeding $€ 80$ billion. PO3 is a global engineering and electronics company with an annual revenue of $€ 78$ billion. PO4 is a joint venture of six large manufacturers and a German software company. PO4 is thus characterized by shared ownership. All POs offer B2B IoT platforms and have the goal to attract more complementors, who develop IoT apps in high quality, to their ecosystem. Both complementors and end-users represent firms.

\subsection{Data Collection}

To collect the material required for the multiple case study analysis, data was retrieved from primary and secondary sources [47]. Although the focus of this empirical inquiry laid on primary data, using semi-structured interviews $(n=13)$, the coherent presentation of all cases required secondary data, such as company websites and internal documents, to fill potential knowledge gaps. The interview questions followed a pre-formulated, high-level guideline, which covered information about the IoT platform and the market as well as the cooperative and competitive governance strategies. I conducted all interviews which required me to react to responses given by the respondents, judge the relevance of their statements, and ask further questions if necessary. Each IoT platform case was based on three interviews with platform managers including roles such as vice president and head of IoT. All interviews were conducted in German via telephone from October to December in 2018 (see Table 3).

Table 3: Overview of the Expert Interviews

\begin{tabular}{|c|c|c|c|}
\hline ID & Role & Length & IoT platform \\
\hline A1 & IoT Consulting Manager & $45 \mathrm{~min}$ & \multirow{3}{*}{ Platform 1} \\
\hline $\mathrm{A} 2$ & IoT Product Manager & $53 \mathrm{~min}$ & \\
\hline A3 & Vice President IoT & $25 \mathrm{~min}$ & \\
\hline $\mathrm{B} 1$ & Head of System \& Analytics & $41 \mathrm{~min}$ & \multirow{3}{*}{ Platform 2} \\
\hline $\mathrm{B} 2$ & Head of Trend Evangelist & $60 \mathrm{~min}$ & \\
\hline $\mathrm{B} 3$ & IoT Platform Product Manager & $47 \mathrm{~min}$ & \\
\hline $\mathrm{C} 1$ & Senior Manager Field Application & $53 \mathrm{~min}$ & \multirow{3}{*}{ Platform 3} \\
\hline $\mathrm{C} 2$ & Director Product \& Portfolio IoT & $48 \mathrm{~min}$ & \\
\hline $\mathrm{C} 3$ & IoT Consulting \& Partner Manager & $35 \mathrm{~min}$ & \\
\hline D1 & Senior IoT Sales Manager & $78 \mathrm{~min}$ & \multirow{3}{*}{ Platform 4} \\
\hline D2 & Partner Manager & $30 \mathrm{~min}$ & \\
\hline D3 & Head of Application Portfolio & $47 \mathrm{~min}$ & \\
\hline E1 & Independent IoT Platform Market Expert & $74 \mathrm{~min}$ & \\
\hline Total & 13 Interviews & $636 \mathrm{~min}$ & 4 Cases \\
\hline
\end{tabular}

The interview with E1, an independent researcher, helped to reflect upon all IoT platforms. On average, the interviews lasted 48.9 minutes (arithmetic mean). Together, they resulted in 636 minutes of audio material, which translated into more than 40,000 words after being transcribed in MAXQDA. Only quotes presented in Section 4 were translated into English. 


\subsection{Data Analysis}

The data collection and analysis process occurred iteratively as suggested by Eisenhardt [50] and Yin [47]. The focus was on the discovery of governance mechanisms and their effects on complementary innovation across all cases. The coding followed two major phases. In open coding, 521 codes associated with over 600 interview quotes were created. In axial coding, 37 subcategories were identified that summarized open codes related to governance mechanisms and their stimulating or alleviating manifestation. The subcategories were clustered into 19 categories describing distinct governance mechanisms and their positive and negative effects on complementary innovation. Subsequently, the categories were assigned to the governance strategies. During this process, no other governance strategy was identified. Also, none of the mechanisms reported by the interviewees could have been assigned to the bundling strategy.

\section{$4 \quad$ Findings}

The findings of this paper provide evidence that cooperation with external firms is a major lever for building innovation capabilities in IoT platforms. Table 4 presents the key findings structured in the framework. It illustrates the mechanisms applied by the four POs to govern their complementors and shows their positive $(+)$ and/or negative $(-)$ effects on complementary innovation. Table 4 also highlights the cases that applied specific mechanisms. Since no case applied bundling, the strategy is not presented in this section or Table 4, but discussed later in Section 5. The next sections present the findings in the form of a cross-case analysis guided along the framework.

Table 4: IoT Platform Governance Strategies and Distinct Mechanisms

\begin{tabular}{|c|c|c|c|c|c|c|}
\hline \multirow{2}{*}{\multicolumn{2}{|c|}{ Governance strategies }} & \multirow{2}{*}{$\begin{array}{l}\text { Implications for complementary innovation } \\
(+) \text { Fostering or }(-) \text { impeding mechanisms }\end{array}$} & \multicolumn{4}{|c|}{ Case evidence } \\
\hline & & & 1 & 2 & 3 & 4 \\
\hline \multirow{3}{*}{ 这 } & Opening & $\begin{array}{ll}(+) & \text { Technical \& social boundary resources } \\
(+) & \text { Multi-cloud strategy } \\
(+) & \text { App stores for control \& commercialization } \\
(+/-) & \text { Open source projects } \\
(-) & \text { Data control }\end{array}$ & $\begin{array}{l}X \\
X \\
X\end{array}$ & $\begin{array}{l}X \\
X \\
X \\
X\end{array}$ & $\begin{array}{l}X \\
X \\
X\end{array}$ & $\begin{array}{l}X \\
X\end{array}$ \\
\hline & Alliancing & $\begin{array}{ll}(+) & \text { Partner management programs } \\
(+) & \text { Contractual agreements } \\
(+) & \text { Strategic partnerships } \\
(+/-) & \text { Platform-to-platform partnerships } \\
\end{array}$ & $\begin{array}{l}X \\
X \\
X \\
X\end{array}$ & $\begin{array}{l}X \\
X \\
X \\
X\end{array}$ & $\begin{array}{l}X \\
X \\
X \\
X\end{array}$ & $\begin{array}{l}X \\
X \\
X \\
X\end{array}$ \\
\hline & & $\begin{array}{l}(+) \text { Modular microservice architecture } \\
(+) \text { Organic growth } \\
(+/-) \text { Co-creation projects } \\
(+/-) \text { Coring through acquisitions }\end{array}$ & $\begin{array}{l}X \\
X \\
X\end{array}$ & $\begin{array}{l}X \\
X \\
X \\
X\end{array}$ & $\begin{array}{l}X \\
X \\
X \\
X\end{array}$ & $\begin{array}{l}X \\
X \\
X \\
X\end{array}$ \\
\hline \multirow{2}{*}{ : } & & $\begin{array}{ll}(+) & \text { Market attention } \\
(+/-) & \text { Monetization model of platform owners } \\
(-) & \text { Cannibalization effect }\end{array}$ & $\mathrm{X}$ & $\begin{array}{l}X \\
X\end{array}$ & $\mathrm{X}$ & $\begin{array}{l}X \\
X\end{array}$ \\
\hline & EU Pricing & $\begin{array}{l}(+) \text { Subsidized development tools } \\
(-) \text { Complex subscription-based pricing models } \\
(-) \text { High homing \& switching costs }\end{array}$ & $\begin{array}{l}X \\
X \\
X\end{array}$ & $\begin{array}{l}X \\
X \\
X\end{array}$ & $\begin{array}{l}X \\
X \\
X\end{array}$ & $\begin{array}{l}X \\
X \\
X\end{array}$ \\
\hline
\end{tabular}




\subsection{Opening}

All IoT POs share technical \& social boundary resources with their complementors to facilitate technological development. Technical resources include open APIs, SDKs, and other knowledge provision forms like video-trainings. Developer communities or hackathons represent social instruments that are used for co-creating apps and sharing the platform's roadmap with the ecosystem, e.g., to ensure alignment with the PO.

Moreover, all POs pursue a multi-cloud strategy. This way, IoT platforms can run on different cloud infrastructures, such as AWS, Microsoft or Azure. Third-party firms benefit from this freedom and must not fear potential vendor lock-ins.

Furthermore, PO1 and PO2 offer apps stores (i.e., marketplaces) to commercialize their own and complementary apps. App stores act as an incentive for value capture and equip POs with an instrument to control the quality of complements. PO1, for example, has strict rules that complementary apps must fulfill before they are offered in the store. PO3 promotes third-party marketplaces because of its own smaller range and the costs of building and maintaining the own app store. PO4 does not offer its own marketplace but references the shops of its seven platform sponsors - called a white-label solution.

In addition, while most POs keep their platforms' core functions closed to external developers, PO3 is exceptional. PO3 has established and actively participates in open source projects. While its Eclipse community drives innovative ideas, the coordination requires much organizational effort and can result in imitation by others as reported by an interviewee: "There are good and bad examples [with our open source projects]. [A partner] has recently provided essential features. On the other hand, someone took our platform and made his own offering." [C3]

Furthermore, data was identified as a control mechanism of PO2. By dictating that data generated by the devices of end-users must be stored to a certain degree inside Platform 2, PO2 exercises power and control over all platform participants. Although platform managers of $\mathrm{PO} 2$ emphasized major advantages for end-users, such as central data access, strict rules might curb platform adoption and innovation due to lock-ins.

\subsection{Alliancing}

All POs have partner management programs with rules and regulations that partner firms must obey to engage in platform-related value creation and capture activities. They ensure equality among complementors and their seriousness of engagement. Within these programs, contractual agreements are often used to reduce value capture risks. For example, partner contracts of $\mathrm{PO} 1$ and $\mathrm{PO} 2$ define the protection duration of intellectual property (IP) and the terms and conditions for revenue sharing. Based on the interviews, four types of partners were identified: (1) platform resellers, (2) platform integrators, (3) cloud infrastructure providers, and (4) complementors.

Moreover, POs engage in strategic partnerships characterized by co-specialization and trust. POs preferably collaborate with companies that complement their traditional capabilities and foster their strengths. For example, $\mathrm{PO} 2$ and $\mathrm{PO} 3$ illustrate that partner firms benefit from their large installed base and industrial expertise. In return, partners should add strong data processing and analysis capabilities: "We look for partners who 
are open and interested in investing in long-term, sustainable collaboration. Ideally, these are companies that complement our industry expertise accordingly." [C1]

Furthermore, all POs engage in platform-to-platform partnerships. Two different types were observed: intra- and inter-platform cooperation. Intra-platform cooperation requires two POs to vertically develop a shared technology. For example, PO4's IoT platform is built on top of another company's platform with a horizontal approach, i.e., a platform that serves diverse domains as the technical backbone. Conversely, interplatform cooperation involves two platform providers who are direct competitors and partners at the same time. Their relationship is of co-opetitive nature. For example, PO1 and PO2 collaboratively developed PO2's first platform versions helping PO2 to enter the IoT platform market. Yet, the cooperation eventually resulted in a conflict that was impeding third-party firms to join the platform.

\subsection{Coring}

All IoT platforms encompass a modular microservice architecture. Microservices are autonomously deployable, modular components, which can be mixed and matched by complementors to rapidly develop new software-based products and services.

When it comes to the extension of the platform, POs pursue three different strategies. First, all POs extend the platform through organic growth, which refers to the in-house development of features. Second, besides PO1, all POs have engaged in co-creation projects at the core of the platform. In these, POs and complementors jointly develop core services that benefit all platform participants. While co-creation can increase a platform's growth in features, it results in shared ownership or increased dependence. This downside was evident in the case of PO2 which received much support from PO1 in the development of its first platform versions. As the project led to a buggy platform, it was stopped but affected the mutual trust of the two long-standing business partners. Third, all POs engage in coring through acquisitions. On the one hand, the absorption of third-party firms may decrease overall incentives to develop apps in the future. On the other hand, a technically advanced platform can attract other third-party firms to the platform, increasing the ecosystem's overall innovation capacity. One of the managers of PO3 argued as follows: "Our partners and external developers, who are our focus, benefit from it. Of course, the purchase extends our ecosystem. But the bottom line is that with [an acquired technology], we can develop new apps faster and generate different innovation cycles." [B3] However, managers of PO1 said that the right scope and scale of acquisitions are essential. In 2016, PO1 acquired an Italian cloud provider and a Norwegian company for industrial software solutions. After adding the key IoT features to its platform, PO1 created awareness from industrial business end-users.

\subsection{Entering}

In addition to third-party applications, all POs offer their apps in app stores. If both POs and complementors offer similar apps, there is direct competition. Three possible outcomes were observed based on this initial situation. First, an interviewee from $\mathrm{PO} 2$ stated that intra- and inter-platform competition (i.e., within and outside the ecosystem) 
increases market attention. "[Competition] between different platform and solution providers is also desirable because the market gets so much more attention [...] [and] promotes innovation early since no provider is a market leader at this point in time and there are manifold potentials for optimization." [B2]. However, other platform cases did not report such positive market attention effects based on direct competition.

Second, all POs offer own apps as part of their monetization model and to increase the early adoption of business end-users. For example, $\mathrm{PO} 2$ has entered the market for machine analytics with its own app. With it, $\mathrm{PO} 2$ competes with three complementors who offer similar solutions. Although all apps comprise rather similar features, PO2 profits from the largest number of downloads. This facet shows that end-users prefer apps developed by the platform owner compared to those of third parties. The finding also illustrates that platforms without ready-to-use apps may not convince potential customers to affiliate with it, taking away positive indirect network effects, i.e., growth on one side of the platform leads to growth on the other side of the platform.

Lastly, platform managers of PO4 reported a cannibalization effect that occurred when PO4 launched a new industrial messenger app on one of its marketplaces. The new cloud-based product rivaled an on-premises version of one of its sponsors. As sales of the sponsor decreased PO4 decided to stop offering the new app on its marketplace: "In fact, we have experienced that the [Platform 4] messenger has created more internal and external confusion and absurdly, rivals our own product that we have been selling directly to our customers for many years. We've found that our customers do not understand the difference between the new and our old messenger. Therefore, we are currently very cautious regarding the promotion of the [Platform 4] app" [D4]

\subsection{Pricing}

All POs subsidize complementors with free development tools, such as SDKs or videotrainings to encourage the development of complementary apps. However, their use of subscription-based pricing models results in monthly platform costs based on, e.g., computing power and number of connected devices. This may affect complementors in two ways. First, as both end-users and complementors must pay monthly license fees for platform access, POs create high homing costs. As a result, complementors do not affiliate with more than one IoT platform reducing the possibility to scale profits. Second, once connectivity with hundreds of devices is established, enterprise customers face high switching costs. They increase lock-in effects and make both complementors and end-users more dependent on the focal platform.

\section{Discussion}

This study yields two major findings. First, it shows that five of the six governance strategies are pursued in IoT platforms. This finding contributes to the literature on B2B platforms $[7,14]$ and adds particularly to our knowledge of IoT platforms. Prior work on IoT platforms has examined the importance of different governance mechanisms [1] 
and business models [3]. However, a comprehensive framework of distinct cooperative and competitive governance strategies used in IoT platforms did not exist.

Second, the findings of this study explain how six governance strategies influence complementary innovation. While the cooperative strategies lead to positive effects, the competitive strategies result in rather negative effects or have not yet been applied. Still, the latter are essential to capture some of the value that is co-created upon the platform.

The following sections distill the findings' contributions to research and practice.

\subsection{Contributions to Research}

Opening shifts the locus of value creation from within the firm toward the ecosystem. POs execute this strategy by giving complementors access to boundary resources, cloud infrastructures, and app stores. Often-cited papers on digital platforms present tradeoffs coming with high degrees of openness, such as "openness vs. control" [9] or "diversity vs. appropriability" [34]. Interestingly, none of these negative effects were associated with open B2B IoT platforms. One argument for the absence of destructive effects lies in the IoT platform market's complexity and fragmentation. As the development of new IoT apps requires technical and contextual know-how, only a few complementors can innovate. Thus, network effects are much weaker compared to B2C platforms.

Alliancing intends to establish close interfirm relationships based on cospecialization and trust. The findings of this study confirm that partner management and contractual agreements have positive effects on value co-creation [36, 37, 51]. Moreover, the study reveals two types of platform-to-platform partnerships in the IoT context: intra- and inter-platform cooperation. This conceptualization adds to the notion of inter- and intra-platform competition coined by Tiwana [12].

Coring aims at extending the platform core. IS scholars have argued that modular platform architectures equipped with standard interfaces foster external innovation and ensure sustainable platform development $[10,12,23]$. The evidence of this study is in line with prior findings, that is, microservices function as modular components in IoT platforms. Crucially, POs must improve their capability of rapidly identifying new and promising technologies and integrating them into their own platform - letting the entire ecosystem benefit from them.

Entering is associated with both positive and negative effects on external innovation in academia. While IS and management scholars found predominantly positive effects $[6,26]$, economic scholars suggested destructive effects motivated by capturing higher rents $[7,31,44]$. In the B2B IoT platform context, entry is often performed accidentally when platform owners offer their own apps in their stores. This is done for two reasons. First, many customers request apps developed by the PO himself-possibly due to trust. Second, these apps are part of the owner's revenue model. Thus, entry decisions should balance short-term financial incentives with the benefits of flourishing ecosystems.

Pricing decisions aim at attracting one side to the platform by low prices in order to increase indirect network effects [11, 39, 40,52]. However, IoT platforms cash in from both complementors and end-users. Subsidies are only provided through free boundary resources confirming prior findings [1]. High prices and varying pricing models, such as pay-per-use, impede adoption and increase both homing and switching costs. 
Bundling seeks to spur complementary innovation through positive indirect network effects. POs can combine two or more key services and offer them together in one setthe bundle. End-users become thus attracted by the extensive set of features by a single PO and, in turn, attract more complementors[14, 30, 43]. However, no IoT PO applied this strategy. The absence of the strategy can be explained by the IoT platform market's complexity and ongoing expansion $[4,5]$. Market consolidation and determination of a few leaders may increase the strategy's value in a more competitive and mature market; as then, attracting large quantities of end-users might have a significant effect on overall leadership in the IoT platform market.

\subsection{Contributions to Practice}

The results suggest that POs should coordinate third-party firms through cooperationthe dominant meta-level strategy. This strategy includes three key recommendations for managers. First, platform managers must align the degree of platform openness with their traditional business. Software companies (PO1 and PO4) should open up their platform, but retain control over core functions. This helps to protect their platform core and software-skills in data processing and analytics - their competitive advantage. Conversely, hardware firms (PO2 and PO3) must focus on their capabilities in device management, automation, and engineering. Opening the platform can grow the number of complementors and end-users - without giving away the device-selling business.

Second, POs should build strong partnerships based on co-specialization. Due to the technical complexity and fragmentation of the IoT market [1], collaboration with strong partners is essential to provide end-to-end IoT solutions. This ensures that most IoTrelated needs of enterprise customers can be served by a single firm and its partners. Software firms should build strong partnerships with device integrators. Hardware firms should strengthen their abilities in software development and analytics.

Third, POs should extend the platform through co-creation projects or acquisitions. Cooperation in and across ecosystems can help to accelerate the development of the platform while sharing the costs for the development. Co-creation projects are key to master the technological complexity in the IoT context $[2,28]$. Moreover, managers should also consider coring new technologies through acquisitions. This instrument, if applied at the right scope and scale, can have positive effects on the technical evolution of the platform and thus drive complementary innovation.

\section{Conclusion, Limitations and Future Research}

The goal of this study was to understand which cooperative and competitive governance strategies are applied by IoT platform owners and how they influence complementary innovation. This question was answered by conducting a multiple case study of four IoT platforms involving 13 interviews. The findings of this work show that five of the six governance strategies derived from the literature are applied in IoT platforms. In sum, cooperation is the dominant meta-level strategy. It allows platform owners (1) to share the platform and other resources with the ecosystem (opening), (2) to complement 
own weaknesses utilizing co-specialization with strategic partners (alliancing) and (3) to continuously extend the platform itself (coring). Overall, governing B2B platform ecosystems requires platform owners to balance cooperation for value co-creation and competition for value capture.

This study is not without limitations. First, the empirical inquiry is based on a limited number of IoT platform cases, but appropriate given the complexity of each ecosystem [50]. Second, the case sample does not include companies, which are headquartered outside of Germany, decreasing its potential to compare global differences and to make generalizations for all IoT platforms [47]. Yet, all case firms operate globally. Third, all interviews were conducted within a limited timeframe, which could have possibly reduced the identification of all cooperative and competitive ecosystem dynamics.

Finally, two avenues for future research are provided. First, future studies should test (and extend) the governance strategies framework empirically. Scholars could conduct in-depth case studies of large B2C (e.g., Amazon) or B2B (e.g., Alibaba) platforms that exhibit strong network effects. This might provide more robust findings on cooperative and competitive dynamics. Second, future research should study turnaround conditions that lead to a changed strategic focus from cooperation to competition in IoT platforms. Scholars should use longitudinal studies and factor in the impact of industry standards for this research objective. This might reveal more insights into interfirm relationships as called for by researchers $[18,35]$.

\section{References}

1. Schreieck, M., Hakes, C., Wiesche, M., Krcmar, H.: Governing Platforms in the Internet of Things. In: 8th International Conference on Software Business. pp. 32-46 (2017).

2. Wortmann, F., Flüchter, K.: Internet of things - Technology and valaue added. Bus. Inf. Syst. Eng. 57, 221-224 (2015).

3. Hodapp, D., Remane, G., Hanelt, A., Kolbe, L.M.: Business Models for Internet of Things Platforms: Empirical Development of a Taxonomy and Archetypes. In: Proceedings of Internationale Tagung Wirtschaftsinformatik (2019).

4. IoT Analytics GmbH: IoT Platform Comparison: How the 450 providers stack up, https://iotanalytics.com/iot-platform-comparison-how-providers-stack-up/.

5. Market Research Future: IOT Platform Market Research Report - Forecast 2022 | MRFR, https://www.marketresearchfuture.com/reports/iot-platform-market-1739.

6. Foerderer, J., Kude, T., Mithas, S., Heinzl, A.: Does platform owner's entry crowd out innovation? Evidence from Google Photos. Inf. Syst. Res. 29, 444-460 (2018).

7. Gawer, A., Cusumano, M.A.: Platform leadership: How Intel, Microsoft, and Cisco drive industry innovation. Harvard Business Review Press, Boston (2002).

8. Boudreau, K.J.: Let a thousand flowers bloom? An early look at large numbers of software app developers and patterns of innovation. Organ. Sci. 23, 1409-1427 (2012).

9. Boudreau, K.J.: Open platform strategies and innovation: Granting access vs. devolving control. Manage. Sci. 56, 1849-1872 (2010).

10. Tiwana, A., Konsynski, B., Bush, A.A.: Research Commentary -Platform evolution: Coevolution of platform architecture, governance, and environmental dynamics. Inf. Syst. 
Res. 21, 675-687 (2010).

11. Eisenmann, T., Parker, G.G., Van Alstyne, M.W.: Strategies for two-sided markets. Harv. Bus. Rev. 84, 92-101 (2006).

12. Tiwana, A.: Evolutionary competition in platform ecosystems. Inf. Syst. Res. 26, 266-281 (2015).

13. Tiwana, A.: Platform ecosystems: Aligning architecture, governance, and strategy. Elsevier (2014).

14. Karhu, K., Gustafsson, R., Lyytinen, K.: Exploiting and defending open digital platforms with boundary resources: Android's five platform forks. Inf. Syst. Res. 29, 479-497 (2018).

15. Bharadwaj, A., El Sawy, O.A., Pavlou, P.A., Venkatraman, N.: Digital business strategy: Toward a next generation of insights. MIS Q. 37, 471-482 (2013).

16. Ghazawneh, A., Henfridsson, O.: Balancing platform control and external contribution in third-party development: The boundary resources model. Inf. Syst. J. 23, 173-192 (2013).

17. Schreieck, M., Wiesche, M.: The platform owner's challenge to capture value - Insights from a business-to-business IT platform. In: Proceedings of the 38th International Conference on Information Systems (ICIS) (2017).

18. Huang, P., Ceccagnoli, M., Forman, C., Wu, D.J.: Appropriability mechanisms and the platform partnership decision: Evidence from enterprise software. Manage. Sci. 59, 102-121 (2013).

19. Perrons, R.K.: The open kimono: How Intel balances trust and power to maintain platform leadership. Res. Policy. 38, 1300-1312 (2009).

20. Armstrong, M.: Competition in two-sided markets. RAND J. Econ. 37, 668-691 (2006).

21. Gawer, A., Henderson, R.: Platform owner entry and innovation in complementary markets: Evidence from Intel. J. Econ. Manag. Strateg. 16, 1-34 (2007).

22. Gawer, A.: Bridging differing perspectives on technological platforms: Toward an integrative framework. Res. Policy. 43, 1239-1249 (2014).

23. Yoo, Y., Henfridsson, O., Lyytinen, K.: Research commentary - The new organizing logic of digital innovation: An agenda for information systems research. Inf. Syst. Res. 21, 724 735 (2010).

24. Eaton, B., Elaluf-Calderwood, S., Sørensen, C., Yoo, Y.: Distributed tuning of boundary resources: The case of Apple's iOS service system. MIS Q. 39, 217-243 (2015).

25. Cennamo, C., Ozalp, H., Kretschmer, T.: Platform architecture and quality trade-offs of multihoming complements. Inf. Syst. Res. 29, 461-478 (2018).

26. Li, Z., Agarwal, A.: Platform integration and demand spillovers in complementary markets: Evidence from Facebook's integration of Instagram. Manage. Sci. 63, 3438-3458 (2017).

27. Püschel, L., Röglinger, M., Schlott, H.: What's in a Smart Thing? Development of a MultiLayer Taxonomy. In: 37th International Conference on Information Systems (ICIS) (2016).

28. Guth, J., Breitenbücher, U., Falkenthal, M., Fremantle, P., Kopp, O., Leymann, F., Reinfurt, L.: A Detailed Analysis of IoT Platform Architectures: Concepts, Similarities, and Differences. In: Internet of Everything. pp. 81-101 (2018).

29. Hagiu, A., Wright, J.: Multi-sided platforms. Int. J. Ind. Organ. 43, 162-174 (2015).

30. Bender, B., Gronau, N.: Coring on digital platforms - Fundamentals and examples from the mobile device sector. In: Proceedings of the International Conference on Information Systems (ICIS). pp. 1-19 (2017).

31. Choi, J.P., Stefanadis, C.: Tying, investment, and the dynamic leverage theory. RAND J. 
Econ. 32, 52-71 (2001).

32. Boudreau, K.J.: Platform Boundary Choices \&amp; Governance: Opening-Up While Still Coordinating and Orchestrating. In: Advances in Strategic Management. pp. 227-297 (2017).

33. Niculescu, M.F., Wu, D.J., Xu, L.: Strategic intellectual property sharing: Competition on an open technology platform under network effects. Inf. Syst. Res. 29, 498-519 (2018).

34. West, J.: How open is open enough? Melding proprietary and open source platform strategies. Res. Policy. 32, 1259-1285 (2003).

35. Ceccagnoli, M., Forman, C., Huang, P., Wu, D.J.: Cocreation of value in a platform ecosystem: The case of enterprise software. MIS Q. 36, 263-290 (2012).

36. Huber, T.L., Kude, T., Dibbern, J.: Governance practices in platform ecosystems: Navigating tensions between cocreated value and governance costs. Inf. Syst. Res. 28, 563-584 (2017).

37. Sarker, Sarker, Sahaym, Bjørn-Andersen: Exploring value cocreation in relationships between an ERP vendor and its partners: A revelatory case study. MIS Q. 36, 317 (2012).

38. Jacobides, M.G., Cennamo, C., Gawer, A.: Towards a theory of ecosystems. Strateg. Manag. J. 39, 2255-2276 (2018).

39. Hagiu, A.: Pricing and commitment by two-sided platforms. RAND J. Econ. 37, 720-737 (2006).

40. Hagiu, A.: Two-sided platforms: Product variety and pricing structures. J. Econ. Manag. Strateg. 18, 1011-1043 (2009).

41. Rochet, J.-C., Tirole, J.: Two-sided markets: A progress report. RAND J. Econ. 37, 645-667 (2006).

42. Zhu, K.X., Zhou, Z.Z.: Research note-Lock-In strategy in software competition: Opensource software vs. proprietary software. Inf. Syst. Res. 23, 536-545 (2012).

43. Eisenmann, T., Parker, G.G., Van Alstyne, M.W.: Platform envelopment. Strateg. Manag. J. 32, 1270-1285 (2011).

44. Farrell, J., Katz, M.L.: Innovation, rent extraction, and integration in systems markets. J. Ind. Econ. 48, 413-432 (2000).

45. Toppenberg, G., Henningsson, S., Eaton, B.: Reinventing the platform core through acquisition: A case study. In: 49th Hawaii International Conference on System Sciences (HICSS). pp. 4634-4643. IEEE (2016).

46. Gawer, A., Cusumano, M.A.: How companies become platform leaders. MIT Sloan Manag. Rev. 49, 28-38 (2008).

47. Yin, R.K.: Case study research : design and methods. SAGE Publications (2014).

48. Webster, J., Watson, R.T.: Analyzing the past to prepare for the future: Writing a literature review. MIS Q. 26, 13-23 (2002).

49. vom Brocke, J., Simons, A., Riemer, K., Niehaves, B., Plattfaut, R., Cleven, A.: Standing on the Shoulders of Giants: Challenges and Recommendations of Literature Search in Information Systems Research. Commun. Assoc. Inf. Syst. 37, 205-224 (2015).

50. Eisenhardt, K.M.: Building theories from case study research. Acad. Manag. Rev. 14, 532550 (1989).

51. Kapoor, R., Lee, J.M.: Coordinating and competing in ecosystems: How organizational forms shape new technology investments. Strateg. Manag. J. 34, 274-296 (2013).

52. Economides, N., Katsamakas, E.: Two-sided competition of proprietary vs. open source technology platforms and the implications for the software industry. Manage. Sci. 52, $1057-$ 1071 (2006). 